\title{
The Effect of Saccharolactone on Rat Intestinal Absorption of Bilirubin in the Presence of Human Breast Milk
}

\author{
GLENN R. GOURLEY, MARK F. GOURLEY, RICHARD AREND, AND MARI PALTA
}

Departments of Pediatrics [G.R.G., R.A.] and Medicine [M.F.G.], and Biostatistics Center [M.P.], University of Wisconsin School of Medicine and Waisman Center on Mental Retardation and Human Development [G.R.G., R.A.J, Madison, Wisconsin 53706

\begin{abstract}
. $\beta$-glucuronidase hydrolyzes glucuronic acid from bilirubin glucuronides. The unconjugated bilirubin that results is more readily absorbed from the intestine. Human breast milk has significant $\beta$-glucuronidase activity, and it has been suggested that the milk may play an etiologic role in the hyperbilirubinemia commonly seen in breast-fed infants. To test whether breast-milk can facilitate intestinal bilirubin absorption, pairs of rats were fitted with bile duct and duodenal catheters. One rat of each pair received an intraduodenal infusion of rat bile plus breastmilk; the other rat received a similar amount of bile and milk plus the $\beta$-glucuronidase inhibitor saccharolactone. Rats receiving saccharolactone excreted significantly less bilirubin in their bile, suggesting that inhibition of $\beta$ glucuronidase decreased intestinal absorption of bilirubin. These findings were not seen in similar experiments when saline was substituted for human breast-milk. (Pediatr Res 25:234-238, 1989)
\end{abstract}

Jaundice is more common in breast-fed than formula-fed neonates. In a combined review of 12 studies totaling more than 8000 infants, moderate jaundice (serum bilirubin $\geq 12 \mathrm{mg} / \mathrm{dl}$ or $205 \mu \mathrm{mol} / \mathrm{liter}$ ) was found in $12.9 \%$ of the 3997 breast-fed infants and $4 \%$ of the 4255 formula-fed infants; $p=3 \times 10^{-10}$ (1). In these studies, known causes of jaundice (e.g. blood group incompatibility, sepsis, hematoma) were excluded or statistically controlled. In breast-fed neonates, the most common etiology for moderate jaundice has been shown to be indeterminate (2).

Although the association between breast milk feedings and neonatal hyperbilirubinemia was described in the mid-1960s (3, 4), the explanation(s) for this association remains unclear. Attempts to relate the jaundice to breast milk levels of either the steroid pregnane- $3 \alpha, 20 \beta$-diol (5), or lipase and FFA (6-8) have been seriously disputed $(9-12)$.

Another hypothesis suggests that jaundice develops because of increased absorption of bilirubin (13). Recently, data from two independent groups have suggested that $\beta$-glucuronidase may be involved with such a mechanism. Both groups showed statistically significant associations between breast milk $\beta$-glucuronidase activity and neonatal serum bilirubin levels $(14,15)$. Elevated intestinal levels of $\beta$-glucuronidase may result in increased hydrolysis of bilirubin glucuronides to produce unconjugated bilirubin. Bilirubin, which is fat soluble and nonpolar, has been

Received July 18, 1988; accepted October 26, 1988

Correspondence and reprint requests Glenn R. Gourley, M.D. University of Wisconsin Waisman Center, Rm 609, 1500 Highland Avenue, Madison, WI 53706

Supported by NIH Grants HD 03352, AM 01077, and HD 20914. shown to be more easily absorbed from the intestine than the more water-soluble, polar bilirubin glucuronides $(16,17)$. Hence, it is suggested that $\beta$-glucuronidase increases the enterohepatic circulation of bilirubin, thus delaying bilirubin clearance from the body and prolonging neonatal jaundice.

If $\beta$-glucuronidase of breast milk contributes to neonatal hyperbilirubinemia, inhibition of this enzyme might decrease the enterohepatic circulation of bilirubin, thereby promoting increased fecal excretion of bilirubin. Saccharo-1,4-lactone is a competitive inhibitor of $\beta$-glucuronidase (18). The purpose of this research was to examine the effect of saccharo-1,4-lactone on the rat's intestinal absorption of bilirubin in the presence of human breast milk.

\section{MATERIALS AND METHODS}

Male Sprague-Dawley rats (Sprague-Dawley, Madison, WI), weighing approximately $250 \mathrm{~g}$ each, were housed in suspended cages for at least $1 \mathrm{wk}$ before experimental study. Animals were given a standard rat food, and a 12-h light-dark cycle was maintained (0600-1800 light). Animals were fasted approximately $16 \mathrm{~h}$ before each experiment with free access to water.

Bile for intraduodenal infusion was prepared in the following manner. Bile was collected as previously described (19), with the following modifications. Anesthesia was initiated with diethyl ether by inhalation to increase excretion of bilirubin monoglucuronide (19) as is seen in bile from human neonates $(20,21)$. After approximately 30-60 min of ether, anesthesia was continued using only intravenous pentobarbital in 2.5-mg doses, given as needed to keep the rat immobile. A solution of $5 \%$ dextrose in $0.9 \%$ saline was given as a continuous intravenous infusion (intravenous syringe pump, Harvard Apparatus Co. Inc., Millis, MA) at a maintenance rate of $100 \mathrm{ml} / \mathrm{kg}$ body wt/day (22). A solution of bilirubin was prepared and infused as described by Natzschka and Odell (23), with the following specifications. Bilirubin solutions were freshly prepared under reduced lighting by dissolving $200 \mathrm{mg}$ of crystalline bilirubin (Sigma Chemical Co., St. Louis, MO) in a solution containing $0.52 \mathrm{~g}$ of $\mathrm{Na}_{2} \mathrm{CO}_{3}$ and $0.52 \mathrm{~g}$ of $\mathrm{NaCl} / 100 \mathrm{ml}$. Once bile collection was under way, each rat received a priming bolus of $2 \mathrm{mg}$ bilirubin/ $100 \mathrm{~g}$ body wt, followed by a constant infusion of $0.1 \mathrm{mg} / 100 \mathrm{~g}$ body wt/ min. Bile was collected for up to $8 \mathrm{~h}$ or until the animal expired. EDTA and sodium ascorbate were added to bring the final concentrations to $5 \mathrm{nM}$ and $20 \mathrm{mM}$, respectively, to preserve bile pigments. Bile collections were pooled and stored in $1-\mathrm{ml}$ aliquots in light-protected containers at $-70^{\circ} \mathrm{C}$ until thawing on the morning of use. Bile was stored no longer than $7 \mathrm{wk}$ before use. Total bilirubin concentration in this bile, as determined using a micromodification of the method of Malloy and Evelyn (24), was $88.2 \mathrm{mg} / \mathrm{dl}$. The vol of bile used for each intraduodenal 
infusion was $0.34 \mathrm{ml}$. An aliquot of the infusion bile $(5 \mu \mathrm{l})$ was analyzed by HPLC as described below, in order to determine the relative proportion of bilirubin mono- versus diglucuronide (these were the predominant bilirubin conjugates present, and their total has been normalized for purposes of description). Bile used for intestinal infusions had a mean bilirubin diglucuronide:monoglucuronide ratio of $0.82 \pm 0.07$ (for the breast milk mixtures, $n=5$ ) and $0.82 \pm 0.03$ (for the saline mixtures, $n=$ 6).

Human breast milk for intraduodenal infusion was prepared in the following manner. Samples of frozen breast milk were obtained from three mothers. Samples were pooled and stored at $-20^{\circ} \mathrm{C}$ in $4-\mathrm{ml}$ aliquots. Milk was stored no longer than $3 \mathrm{wk}$ before use. $\beta$-glucuronidase activity, measured as previously described (14), was 242 modified Sigma U/ml. Freeze-thaw had negligible effect on milk $\beta$-glucuronidase activity. A total of 42 human breast milk samples stored frozen for up to $622 \mathrm{~d}$ showed no significant change in $\beta$-glucuronidase activity after thawing (Student's paired $t$ test). When $1 \mathrm{ml}$ of this breast milk was mixed with $0.25 \mathrm{ml}$ of the above-described bile, the $\beta$-glucuronidase activity of the milk was increased to 278 modified Sigma U/ml.

Experiments consisting of bile collections before, during, and after intraduodenal infusion of mixtures of rat bile and human breast milk, with or without added saccharolactone, were initiated at approximately 0800 . These experiments were done in a paired manner so that each d two rats were studied, one in the saccharolactone group and one in the saline control group. The group to go first was alternated from day to day. Operations and determinations in the second rat followed those of the first by 30 to $60 \mathrm{~min}$. After being weighed, each animal received $25 \mu \mathrm{mol} /$ $\mathrm{kg}$ body wt of Sn-protoporphyrin subcutaneously. Sn-protoporphyrin (Porphyrin Products, Logan, UT) had been prepared as described by Simionatto et al. (25). Pentobarbital, $35 \mathrm{mg} / \mathrm{kg}$, was then given intraperitoneally. No ether was administered during these bile collections. When appropriate anesthesia was achieved, the femoral vein was cannulated with PE-10 tubing and a similar dose of Sn-protoporphyrin was immediately given intravenously. The purpose of the Sn-protoporphyrin was to prevent formation of bilirubin from heme generated by the surgery (25). The tip of a PE-90 cannula was sutured into the proximal duodenum after making a small incision in the intestinal wall, being careful to avoid blood vesseis and to achieve hemostasis. The bile duct was then cannulated with PE-10 tubing, the abdomen closed, and the animals were secured in a "belly-down" position for the next $7.5 \mathrm{~h}$ of the bile collection. The time from initial pentobarbital administration until initiation of bile collection ("surgery time) was noted for all rats. Additional intravenous pentobarbital (50 $\mathrm{mg} / \mathrm{ml}$ ) was given during the period of bile collection in $2.5-\mathrm{mg}$ doses, as needed to keep each rat immobile. Total pentobarbital given was recorded for each rat. Each collection period lasted 30 min. During the bile collection, each rat was given intravenous $5 \%$ dextrose in $0.9 \%$ saline as described above. Bile collections were done in the dark except for an overhead incandescent heating lamp, which was used as needed to maintain body temperature between 37 and $37.4^{\circ} \mathrm{C}$. Body temperature was monitored continuously with an electronic rectal temperature probe (Bailey Instruments, Saddle Brook, NJ). All tubing was shielded from light with aluminum foil. Bile was collected in light-protected iced containers.

After a 2-h baseline bile collection, each rat received an intraduodenal infusion of a mixture of human breast milk $(4 \mathrm{ml})$ plus bile $(0.34 \mathrm{ml})$ (both described above) plus either saccharolactone $(10 \mathrm{mg}$ in $0.1 \mathrm{ml}$ of $0.9 \%$ saline) or $0.9 \%$ saline. Previous experiments had shown this dose of saccharolactone to inhibit $100 \%$ of the $\beta$-glucuronidase activity present in the human breast milk used. The saline-containing mixture was adjusted to the same $\mathrm{pH}$ as that of the saccharolactone mixture with the addition of several drops of $0.2 \mathrm{M}$ sodium acetate. This infusion was delivered over $2 \mathrm{~min}$. The human breast milk and rat bile samples for each rat pair came from the same freshly thawed and warmed aliquots of milk and bile. Animals were alive and stable throughout the course of these and subsequently described bile collections.

A second group of similar paired experiments was performed in which saline was substituted for human breast milk. In this group of experiments, the $\mathrm{pH}$ of the saccharolactone mixture was adjusted to the same pH range (approximately 5.6) as that of the breast milk plus saccharolactone group with the dropwise addition of $0.25 \mathrm{M} \mathrm{NaOH}$. The $\mathrm{pH}$ of the nonsaccharolactonecontaining mixture was adjusted to the same range with $0.2 \mathrm{M}$ sodium acetate.

Bile flow was determined gravimetrically, and wt was converted to vol using a factor of 0.98 , based on a bile sp gr of 1.021 (23). Total bilirubin was determined immediately after collection as noted above. EDTA and sodium ascorbate were added to the remaining bile to bring the final concentration to $5 \mathrm{nM}$ and 20 $\mathrm{mM}$, respectively. Bilirubin excretion was expressed as $\mu \mathrm{g}$ bilirubin equivalents $/ 100 \mathrm{~g}$ body $\mathrm{wt} / \mathrm{min}$.

Bile pigments were separated, identified, and analyzed using an HPLC system consisting of a Perkin-Elmer series 410 solvent delivery system (Perkin-Elmer Corp., Norwalk, CT), ISS-100 automatic sample injector with sample tray perfused by a MGW Lauda RM6 refrigerated circulator (Lauda Div., Brinkman Instruments Co., Westbury, NY), and a Hewlett-Packard 1040A diode array detector (Hewlett-Packard Co., Palo Alto, CA) controlled by a model 310 microcomputer interfaced with a 50 megabyte Bering hard disk. (Bering Industries, Inc., Fremont, CA). Sample vial temperature was monitored continuously using a Bailey temperature probe, and the coolant temperature was adjusted to approximately $-3.4^{\circ} \mathrm{C}$ to keep the sample vial temperature at $1^{\circ} \mathrm{C}$. A linear gradient of acetonitrile in $0.1 \mathrm{M}$ sodium acetate (adjusted to $\mathrm{pH} 4.0$ with glacial acetic acid) without counter ion was used in the following manner: initial $28 \%$ acetonitrile was increased to $34 \%$ over $2 \mathrm{~min}$, with a 12 -min isocratic hold at $34 \%$, followed by an increase to $80 \%$ over 5 min, with a 10 -min isocratic hold at $80 \%$, followed by a return to initial conditions. Vol of bile injected was $20 \mu \mathrm{l}$. Detection was at $436 \mathrm{~nm}$ with a 4-nm bandwidth, minus a reference of 550 $\mathrm{nm}$ with a $50 \mathrm{~nm}$ bandwidth. HPLC bile analysis was performed within $24 \mathrm{~h}$ of bile collection.

The data were analyzed by 2-way ANOVA on within pair differences, using the pair and the time period as factors. This allowed the significance of the treatment to be assessed across the whole course of the experiment. If this analysis showed a significant difference, paired $t$ tests were then performed to determine at which time period the groups differed significantly. All $p$ values are based on 2-tailed analyses; $p>0.05$ was judged not significant. Other statistical analyses utilized Student's $t$ test.

\section{RESULTS}

Comparisons were made first between rats given intraduodenal human breast milk with rat bile and either saccharolactone or saline. Second, comparisons were made between rats given intraduodenal saline with rat bile and either saccharolactone or saline.

Table 1 presents descriptive data comparing the groups of rats that were involved in these experiments. There were no significant differences between the groups that were compared with regard to body wt, surgery time, extra pentobarbital sedation required during bile collections, or the $\mathrm{pH}$ of the duodenal infusate. The rats in the breast milk groups weighed significantly less $(\sim 7 \%)$ than those in the saline groups; however, this is inconsequential because a comparison between these groups was not intended.

The effect of saccharolactone versus saline on the human milkfacilitated absorption of bilirubin is presented in Figure 1. The ANOVA shows an overall significantly increased biliary excretion of bilirubin in the group which did not receive saccharolactone $(p<0.05)$. In examining specific time intervals, the data show significant differences at the following times: 3 h $(p<$ 
$0.05), 3.5 \mathrm{~h}(p<0.01), 4 \mathrm{~h}(p<0.02), 4.5-5.5 \mathrm{~h}(p<0.05)$, and $7.5 \mathrm{~h}(p<0.05)$.

Bilirubin excretion is a product of bile flow and bilirubin concentration. There were no significant differences between the two groups with regard to bile flow, which ranged from 6.33 to $4.17 \mu \mathrm{l} / 100 \mathrm{~g}$ body wt/min, slowly decreasing over the course of the collection periods. The difference in bilirubin excretion was due to a significant difference in the bilirubin concentration. The group that received saline produced bile with significantly higher

Table 1. Descriptive data in rats receiving intraduodenal infusions of rat bile plus human breast milk or saline with or without saccharolactone*

\begin{tabular}{lccccc}
\hline & \multicolumn{3}{c}{ Intraduodenal infusion } \\
\cline { 2 - 3 } & \multicolumn{2}{c}{ Breast milk } & & \multicolumn{2}{c}{ Saline } \\
\cline { 2 - 3 } \cline { 6 - 6 } \cline { 5 - 6 } & \multicolumn{2}{c}{ Saccharolactone } & & \multicolumn{2}{c}{ Saccharalactone } \\
\cline { 2 - 3 } \cline { 5 - 6 } & Yes & No & & Yes & No \\
& $(n=7)$ & $(n=7)$ & & $(n=6)$ & $(n=6)$ \\
\hline Wt (g) & 325 & 326 & & 350 & 348 \\
(SD) & $(12)$ & $(9)$ & & $(21)$ & $(16)$ \\
Surgery time (min) & 37.4 & 39.7 & & 37.0 & 32.0 \\
(SD) & $(6.1)$ & $(8.3)$ & & $(6.5)$ & $(3.8)$ \\
Extra pentobarbital (ml) & 0.57 & 0.57 & & 0.67 & 0.65 \\
(SD) & $(0.08)$ & $(0.07)$ & & $(0.03)$ & $(0.05)$ \\
pH of duodenal infusion & 5.63 & 5.70 & & 5.59 & 5.65 \\
(SD) & $(0.14)$ & $(0.13)$ & & $(0.07)$ & $(0.11)$ \\
\hline
\end{tabular}

* Bile was collected for $2 \mathrm{~h}$ before and $5.5 \mathrm{~h}$ after duodenal infusion. During the bile collection, extra intravenous pentobarbital was given in total doses noted below to keep the rats immobile. There are no significant differences within the groups receiving breast milk or saline. Rats in the breast milk groups weighed significantly less than those in the saline groups $(p<$ $0.05)$. bilirubin concentration than did the group which received saccharolactone ( $p<0.05$ overall) (see Fig. 2). In examining specific time intervals, the data show significant differences at the following times: $2.5 \mathrm{~h}(p<0.05), 3-3.5 \mathrm{~h}(p<0.01), 4 \mathrm{~h}(p<0.02)$, $4.5-5.5 \mathrm{~h}(p<0.05)$, and $7.5 \mathrm{~h}(p<0.05)$.

To assess whether the differences observed in Figure 1 could be due to the effect of the saccharolactone alone, a similar analysis of biliary bilirubin excretion was conducted in the second group of rats which received intraduodenal saline, rat bile, and either saccharolactone or saline. These data are presented in Figure 3. No significant differences were found between these groups using the experiment-wide 2-way ANOVA. As additional confirmation, individual collection periods were compared with paired $t$ tests. Again, no significant differences were noted. It is of interest that the group receiving saccharolactone demonstrated a lower mean biliary bilirubin excretion at all time points after the infusion. If this order persisted for a much greater number of rats, a statistically significant difference might arise. The lack of any significant difference after identical statistical analyses of a similar number of observations as were made in Figure 1 suggests that the findings are not due to saccharolactone alone.

HPLC analysis of the bile pigment composition of the biliary collections showed no significant differences within either the human breast milk with or without saccharolactone comparisons or the saline with or without saccharolactone comparisons. This analysis included comparisons of the relative percentages of bilirubin diglucuronide, bilirubin C-8 monoglucuronide, bilirubin $\mathrm{C}-12$ monoglucuronide, and $\mathrm{C}-8 / \mathrm{C}-12$ ratio. There was a significant variation with time in these parameters, however, no significant overall differences between comparable groups could be demonstrated. Values for the bilirubin conjugates were similar in all four groups. Bilirubin diglucuronide content varied from $45-57 \%$ of the total bile pigment; bilirubin C-8 monoglucoronide varied from $26-32 \%$; and bilirubin C-12 monoglucuronide varied from $17-22 \%$. The bilirubin diglucuronide:monoglucuronide

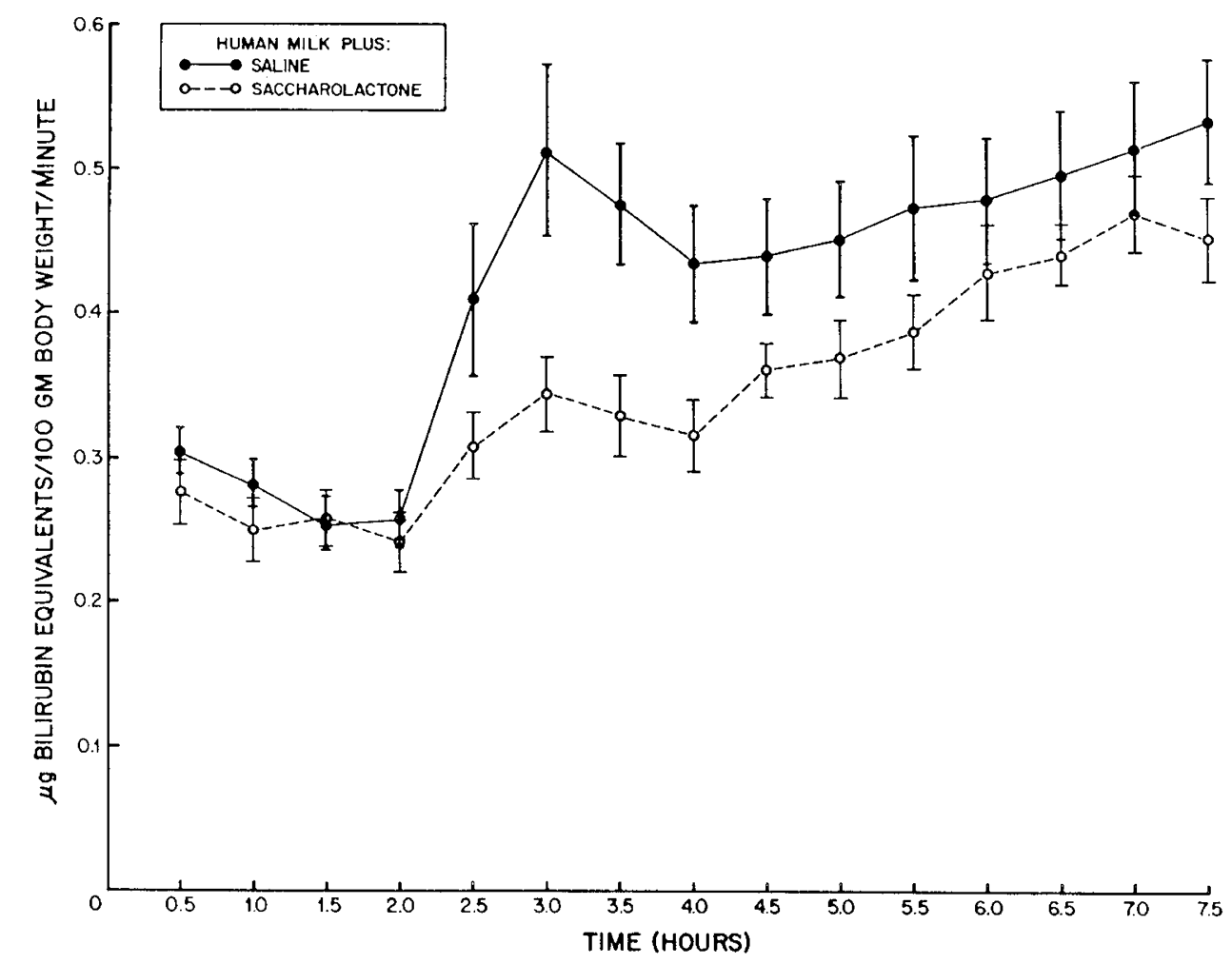

Fig. 1. Biliary bilirubin excretion in seven pairs of rats given intraduodenal mixtures of human breast milk and rat bile plus either saccharolactone (broken lines) or saline (solid lines). Intraduodenal infusions were made after an initial 2-h baseline period. Data are presented as mean \pm SEM. ANOVA shows significantly higher bilirubin excretion in the rats that did not receive saccharolactone $(p<0.05$, overall; with $p<0.01$ at $3.0 \mathrm{~h})$. 


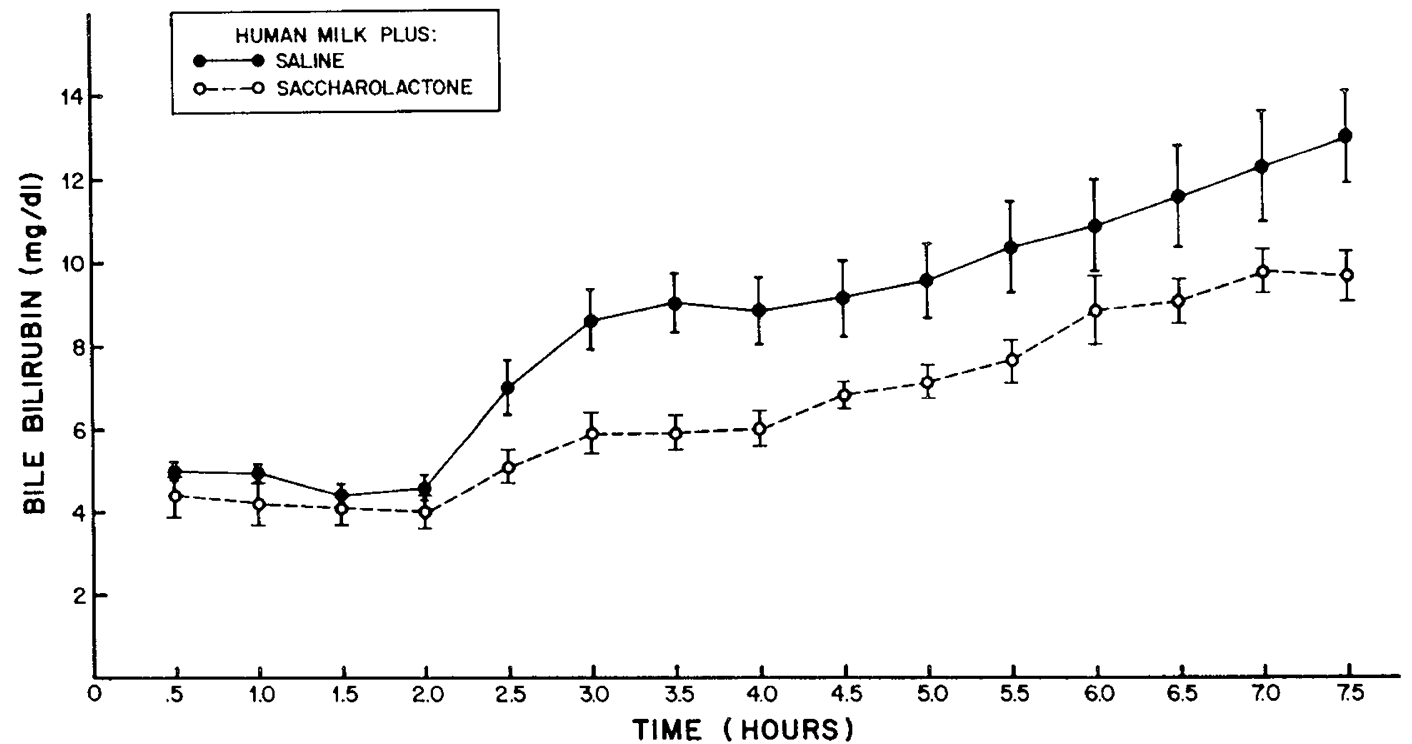

Fig. 2. Bile bilirubin concentration in seven pairs of rats given intraduodenal mixtures of human breast milk and rat bile plus either saccharolactone (broken lines) or saline(solid lines). Intraduodenal infusions were made after an initial 2-h baseline period. Data are presented as mean \pm SEM. ANOVA shows significantly higher bilirubin concentrations in the bile of the rats that did not receive saccharolactone $(p<0.05$, overall; with $p<$ 0.01 at 3 and $3.5 \mathrm{~h}$ ).

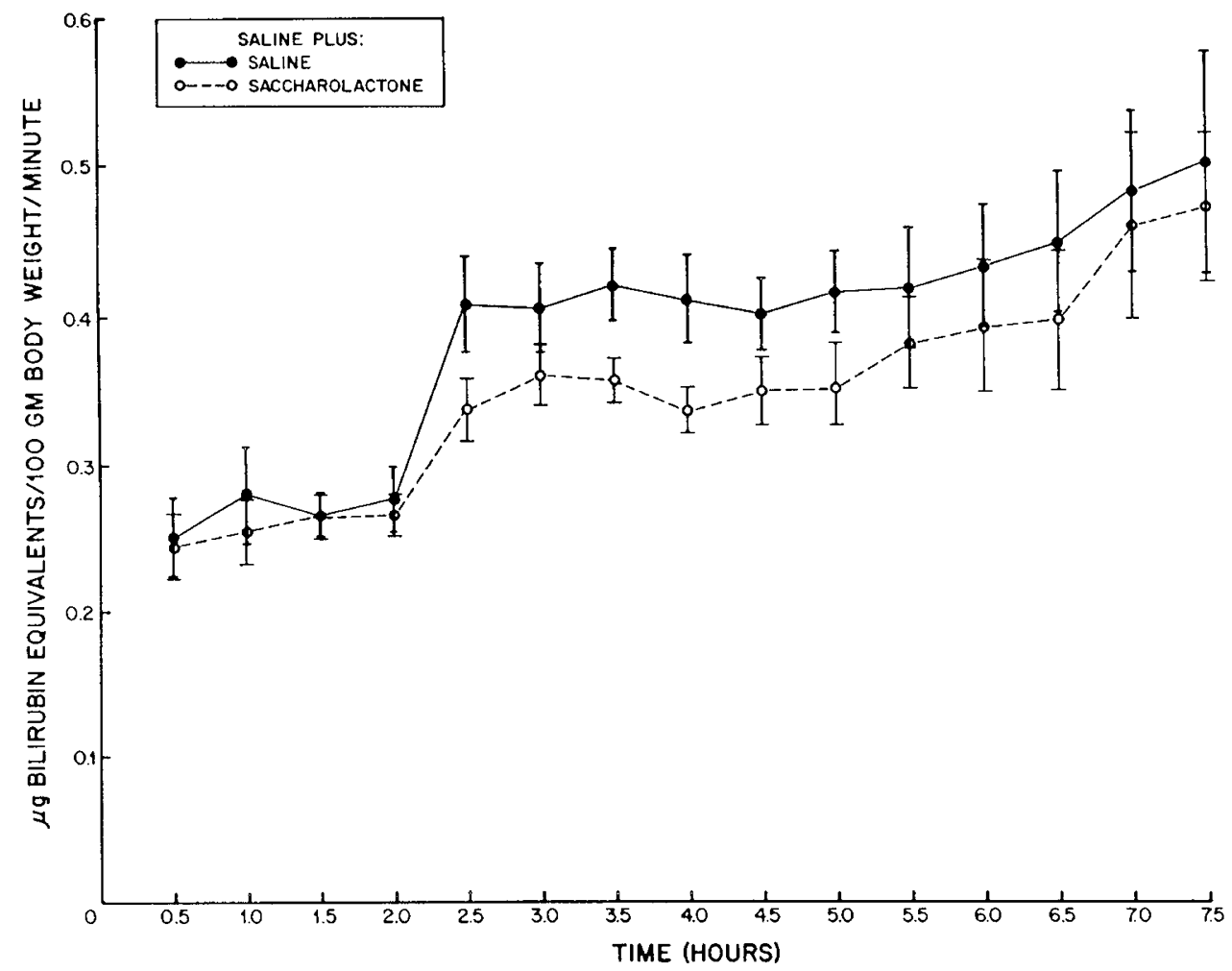

Fig. 3. Biliary bilirubin excretion in six pairs of rats given intraduodenal mixtures of saline and rat bile plus either saccharolactone (broken lines) or saline (solid lines). Intraduodenal infusions were made after an initial 2-h baseline period. Data are presented as mean \pm SEM. ANOVA shows no significant difference between the two groups overall or at specific times.

ratio varied from $0.90-1.26$. The bilirubin $\mathrm{C}-8 / \mathrm{C}-12$ :monoglucuronide ratio varied from $1.18-1.44$.

\section{DISCUSSION}

The purpose of these experiments was to examine intestinal bilirubin absorption in the rat after the intraduodenal infusion of mixtures of conjugated bilirubin in bile plus human breast milk. In this model, unconjugated bilirubin absorbed from the intestine circulates through the bloodstream to the liver where it is conjugated and excreted into the bile. Hence, biliary bile pigment excretion can be directly correlated with intestinal absorption of bilirubin.

Intestinal absorption of bilirubin is more of a concern in neonates than in adults for two reasons. First, bilirubin conjugates in neonatal bile are principally monoglucuronides $(20,21)$ rather than diglucuronides which predominate in normal adult bile (26). Hence, hydrolysis of only one glucuronic acid moiety results in unconjugated bilirubin in the neonate, whereas similar hydrolysis yields bilirubin monoglucuronide in adult bile. Thus, a given amount of $\beta$-glucuronidase activity produces more unconjugated bilirubin in the neonate. Second, intestinal bacteria 
convert bilirubin conjugates to urobilinogens in adults, thus protecting against bilirubin absorption (27). However, the developing flora of the neonate's intestine produces very little urobilinogen (13).

Control and experimental rats experienced similar conditions as they lay side by side for the 7.5-h bile collection. Sn-protoporphyrin was used to block the production of bilirubin from surgically produced blood, thus making baseline bilirubin excretion quite stable. When the first two groups (i.e. breast milk with and without saccharolactone) exhibited the hypothesized difference in bile pigment excretion, two additional groups were compared. In this additional comparison, saline was substituted for breast milk to address the possibility that the initial findings might be due to the saccharolactone alone. Because rats are coprophagic, one might argue that the bacterial $\beta$-glucuronidase of the upper intestine might be responsible for significant deconjugation of the infused bilirubin glucuronide. Inhibition of this bacterial $\beta$-glucuronidase by saccharolactone might be suggested to explain the observed difference. Alternatively, the difference might be considered to be due to an effect of saccharolactone on some other step in the enterohepatic circulation of bilirubin. This second pair of rat groups weighed significantly more than the first two groups, thus precluding a simultaneous comparison of all four groups. However, in the second comparison, in which saline was substituted for breast milk and infusions were done with and without saccharolactone, there was no significant difference between the two groups in the biliary bile pigment excretion. This rules against the observed effect being caused by the saccharolactone itself. Further, the very rapid increase in bile pigment excretion following intraduodenal infusion of the bilirubin-containing mixture suggests absorption of bilirubin from the small intestine. Studies of intestinal deconjugation of bilirubin in germfree and conventional rats indicate that the caecum rather than the small intestine is the major site of bacterial deconjugation (28).

Gartner et al. (29) have previously suggested that breast milk may promote the intestinal absorption of bilirubin. However, there are important differences between their studies and those presented here. Gartner et al. (29) delivered unconjugated bilirubin into the rat duodenum and showed that certain breast milk samples facilitated bilirubin absorption. No specific etiologic mechanism to explain this was tested. As bile contains very little unconjugated bilirubin we thought that it would be more physiologic to infuse rat bile, which is predominantly conjugated bilirubin. By using saccharolactone as a $\beta$-glucuronidase inhibitor, we addressed a specific mechanism for the facilitated intestinal absorption of bilirubin. $\beta$-glucuronidase could play no role in explaining the findings of Gartner et al. because the bilirubin infused was already unconjugated.

As bile has been shown to be inhibitory to bacterial $\beta$-glucuronidase activity, with a significant positive correlation between biliary $\mathrm{D}$-glucaric acid content and $\beta$-glucuronidase inhibition (30), we measured the $\beta$-glucuronidase activity in our duodenal infusion mixture of bile and breast milk. We demonstrated no inhibition of $\beta$-glucuronidase in this mixture.

We believe that these studies support the hypothesis that breast milk $\beta$-glucuronidase may be a significant factor related to the hyperbilirubinemia more commonly seen in breast-fed than formula-fed infants.

Acknowledgments. The authors thank Dr. Gerard B. Odell for helpful comments during preparation of the manuscript.

\section{REFERENCES}

1. Schneider AP 1986 Breast milk jaundice in the newborn-a real entity. JAMA 255:3270-3274

2. Osborn LM, Reiff MI, Bolus R 1984 Jaundice in the full-term neonate Pediatrics 73:520-525

3. Newman AJ, Gross S 1963 Hyperbilirubinemia in breast fed infants. Pediatrics 32:995-1001

4. Gartner LM, Arias IM 1966 Studies of prolonged neonatal jaundice in the breast-fed infant. J Pediatr 68:54-66

5. Arias IM, Gartner LM, Seifter S, Furman M 1964 Prolonged neonatal unconjugated hyperbilirubinemia associated with breast feeding and a steroid, pregnane-3(alpha),20(beta)-diol in maternal milk that inhibits glucuronide formation in vitro. J Clin Invest 43:2037-2047

6. Bevan BR, Holton JB 1972 Inhibition of bilirubin conjugation in rat liver slices by free fatty acids, with relevance to the problem of breast-milk jaundice. Clin Chim Acta 41:101-107

7. Foliot A, Ploussard JP, Housset E, Christoforov B, Luzeau R, Odievre M 1976 Breast-milk jaundice: in vitro inhibition of rat liver bilirubin-UDP-glucuronyltransferase activity and $\mathrm{Z}$ protein bromosulfophthalein binding by human milk. Pediatr Res 10:594-598

8. Poland RL, Schultz GE, Gayatri G 1980 High milk lipase activity associated with breast-milk jaundice. Pediatr Res 14:1328-1331

9. Murphy JF, Hughes I, Verrier Jones ER, Gaskell S, Pike AW 1981 Pregnanediols and breast-milk jaundice. Arch Dis Child 56:474-476

10. Hernell O 1982 Breast-milk jaundice. J Pediatr 99:311-312

11. Constantopoulos A, Messaritakis J, Matsaniotis N 1980 Breast-milk jaundice: the role of lipoprotein lipase and the free fatty acids. Eur J Pediatr 134:3538

12. Lathe GH 1976 Neonatal bilirubin metabolism in relation to jaundice. Clin Endocrinol Metab 1:107-122

13. Broderson R, Hermann LS 1963 Intestinal reabsorption of unconjugated bilirubin-a possible contributing factor in neonatal jaundice. Lancet 1:1242

14. Gourley GR, Arend RA $1986 \beta$-glucuronidase and hyperbilirubinaemia in breast-fed and formula-fed babies. Lancet 1:644-646

15. Gaffney PT, Buttenshaw RL, Ward M, Diplock RD 1986 Breast milk $\beta$ glucuronidase and neonatal juandice. Lancet 1:1161-1162

16. Gilbertsen AS, Bassenmaier I, Cardinal R 1962 Enterohepatic circulation of unconjugated bilirubin in man. Nature 196:141-142

17. Lester R, Schmid R 1963 Intestinal absorption of bile pigments: I: the enterohepatic circulation of bilirubin in the cat. J Clin Invest 42:736-746

18. Keiler RK, Touster O 1975 Spectral studies of conformational changes induced in $\beta$-glucuronidase by saccharo-1,4-lactone. $\mathrm{J}$ Biol Chem 250:2739-2744

19. Gourley GR, Mogilevsky W, Arend RA, Siegel FL, Odell GB 1985 Effects of anesthetic agents on bile pigment excretion in the rat. Hepatology 5:610614

20. Fevery J, Blanckaert N, Berthelot P, Heirwegh KPM 1979 Bilirubin metabolism in neonatal life. In: Javitt BN (ed) Neonatal Hepatitis and Biliary Atresia. Government Printing Office, Washington, DC, pp 251-266

21. Blumenthal SG, Taggart DB, Rasmussen RD, Ikeda RM, Ruebner BH, Bergstrom DE, Hanson FW 1979 Conjugated and unconjugated bilirubins in humans and Rhesus monkeys. Structural identity of bilirubins from biles and meconiums of newborn humans and Rhesus monkeys. Biochem J 179:537-547

22. Baker HJ, Lindsey JR, Weisbroth SH 1979 Selected normative data from the laboratory rat. In: Baker HJ, Lindsey JR, Weisbroth SH (eds) The Laboratory Rat, vol 1. Academic Press New York, pp 411-412

23. Natzschka JC, Odell GB 1966 The influence of albumin on the distribution and excretion of bilirubin in jaundiced rats. Pediatrics 37:51-61

24. Odell GB 1980 In: Neonatal Hyperbilirubinemia. Grune and Stratton, New York, pp 143-144

25. Simionatto CS, Anderson KE, Drummond GS, Kappas A 1985 Studies on the mechanism of Sn-protoporphyrin suppression of hyperbilirubinemia-inhibition of heme oxidation and bilirubin production. J Clin Invest 75:513521

26. Fevery J, Van Damme B, Mechiel R, De Groote J, Heirwegh KPM 1972 Bilirubin conjugates in bile of man and rat in the normal state and in liver disease. J Clin Invest 51:2482-2492

27. Watson CJ, Campbell M, Lowry PT 1958 Preferential reduction of conjugated bilirubin to urobilinogen by normal fecal flora. Proc Soc Exp Biol Med 98:707-711

28. Saxerholt H, Midtvedt T 1986 Intestinal deconjugation of bilirubin in germfree and conventional rats. Scand J Clin Lab Invest 46:341 -344

29. Gartner LM, Lee K-S, Moscioni AD 1983 Effect of milk feeding on intestinal bilirubin absorption in the rat. $J$ Pediatr 103:464-471

30. Yamaguchi I, Sato T, Matsushiro T, Sato H 1965 Quantitative determination of D-glucaric acid in bile in relation to inhibitory effect of bile on bacterial $\beta$-glucuronidase. Tokohu J Exp Med 87:123-132 